\title{
Predictors of Sexual-Risk behaviours among Youth in Ibadan North- West Local Government Area, Oyo state, Nigeria
}

\author{
Article by Beyioku Adedoyin Mary ${ }^{1}$; Kemnele, Kelechi Degbetamara Kenneth ${ }^{2}$, Okon, Atai \\ Bassey $^{3}$; Joel, Mercy Oiza ${ }^{4}$ \\ 1,2,3,4 MPH, University Ibadan, Department of Health Promotion and Education, Faculty of \\ Public Health, University College Hospital, Ibadan, Oyo State, Nigeria \\ E-mail: beyiokumary88@gmail.com ${ }^{1,}$ kelechikemnele@gmail.com ${ }^{2}$;okonataibassey@gmail.com ${ }^{3}$ \\ mercyoiza205@gmail.com ${ }^{4}$
}

\begin{abstract}
Background: Sexual-Risk behaviours contribute to the leading causes of morbidity, mortality and social problems among youths. Although there are many studies conducted on this subject, the predictors of sexual-risk behaviours among youths have not been well explored. This study was therefore, designed to contribute to existing knowledge and enhance the development of strategies that will positively influence the perception and attitude of youths regarding sexual health risk related matters.

Methods: A descriptive cross-sectional study design using multistage sampling methods was conducted among randomly selected 360 youths (15-24 years) using data collected via pre-tested interviewer administered semi-structured questionnaire, which measured the following variables: socio-demographic characteristics; sexual-risk behavior and predictors of sexual-risk. Data was analyzed using Chi-square test and binary logistics regression at $p=0.05$. Social learning theory was adopted in the development of the instrument.

Results: Almost half (49.7\%) of the respondents reported to have ever had sex, $57.5 \%$ and $71.2 \%$ of them had sexual intercourse with casual partners and multiple partners respectively, also $68.7 \%$ of them did not use condom during their last sexual activity. Age and gender were the most significant predictors of sexual-risk behavior. Youths aged between 15-17 and 18-20 years are about 5.7 and 3.1 times respectively more likely than those older than 21 years to have an early sexual debut $(O R=5.693, C I=$ 1.205-26.901; 3.067, $C I=1.260-7.465)$ while male youths were about 2.6 times more likely than females to use condoms $(O R=2.563, C I=1.171-5.607)$.

Conclusion: Dearth of information available to youths about sexual health and the dangers associated with risky sexual behaviours can be held responsible for increased levels in participation in sexual-risk behaviours among youths. There is need for concerted effort of all to promote healthy behaviour, via youth-centered programmes and youth targeted behavioural change interventions.
\end{abstract}

Keywords: Youths, Sexual health, Sexual-risk behaviour, Predictors, Ibadan.

\section{Introduction}

Young people generally constitute a very important segment of the population of any nation because of their number and characteristics. They are the nation's most valued human resource due to the role they can play in socio-economic and political situation of the country if appropriately trained and encouraged. They are characterized by Nigerian government as ambitious, enthusiastic, energetic and promising. They are also considered vulnerable in society due to the rapid pace of change they experience at this stage of their lives (Nigeria National Youth Policy, 2009).

Studies in Nigeria has established that young people are vulnerable to sexual risk behaviours, which include early sexual debut, having multiple sexual partners, indulging in unprotected sex, low and inconsistent use of condoms etc. (Echendu, Joseph, Nkemakolam, Chima, Akinsewa, Ejike, 2011).

The youth risk surveillance system monitors six types of health risk behaviours that contribute to the leading causes of death, disability and social problems among youth and adults; one of which is sexual 
DOI: 10.21522/TIJPH.2013.SE.19.01.Art019

ISSN: 2520-3134

health risks. (Centre for Disease Control and Prevention, 2010). Most young people are healthy, however more than 1.8 million young people aged 15 to 24 die each year (World Health Organization, 2008a) due to sexual related problem and other health risks. Worldwide, a very larger number of young people suffer from illnesses which prevent them to grow and develop to their full potential.

It was posited that adolescents in Nigeria have a high burden of reproductive health problems (Ahonsi, 2013). This assertion is supported by earlier surveys conducted on sexual behaviours of Nigerian Adolescents (National Demographic Health Survey, 2008; Federal Ministry of Health, 2011) which indicated that Nigerian adolescent (15-19) almost half of the females (46.2\%) and about a quarter of males $(22.1 \%)$ have engaged in sexual intercourse.

It had been documented that sexually transmitted infections (STIs) are commonly found in young people aged 15-24 years. WHO stated that young people between the ages of 25 years have experienced over 100 million new cases of sexually transmitted infections (STIs) annually. And in Nigeria this same aged group had been found with the highest rate of HIV infection. HIV/AIDS prevalence among all youths is 5.2\% compared to national prevalence at 4.4\% (National Demographic Health Survey, 2013). Prevalence of female youth STD contraction is 17.2\% (Adebowale, Titiloye, Fagbamigbe, Akinyemi, 2013). Studies have also revealed that early sexual debut is another sexual risky practice among young people that contribute to reproductive health problems and diseases. Twenty four percent (24\%) of women had sexual intercourse by age 15 and $54 \%$ by age 18 (NDHS, 2013). In the national HIV survey of 2010, HIV infection rate among the aged 15-19 years old and the 20-24 years old group are 3\% and 4.6\% respectively (Federal Ministry of Health, 2011). 2\% of females aged between 15-24 years and 4\% of males of aged between 15-24 years had two or more sexual partners (NDHS, 2013).

Several studies had been done generally on risky behaviours among in-school and out- school adolescents; most especially on sexual risk behaviours. However, few studies had been carried out on sexual-risk behaviour indulged by young people in Nigeria using a community setting, unlike most studies which were conducted in school settings.

\section{Goal}

The goal of this study was to investigate predictors of sexual-risk behaviours among youths in Ibadan North-West Local Government Area (LGA), Oyo State.

\section{Specific objectives}

1. Identify various sexual-risk behaviours among youths in Ibadan North-West LGA, Oyo State.

2. Identify the predictors of sexual-risk sexual behaviours among youths in Ibadan North-West LGA, Oyo State.

\section{Theoretical frame-work}

The social learning theory was adopted in the course of this research to determine methods by which risky health behaviours can be discouraged. The chart below showcases the relationship between various factors that play significant roles to discourage the involvement of youth in risky sexual health behaviours. 


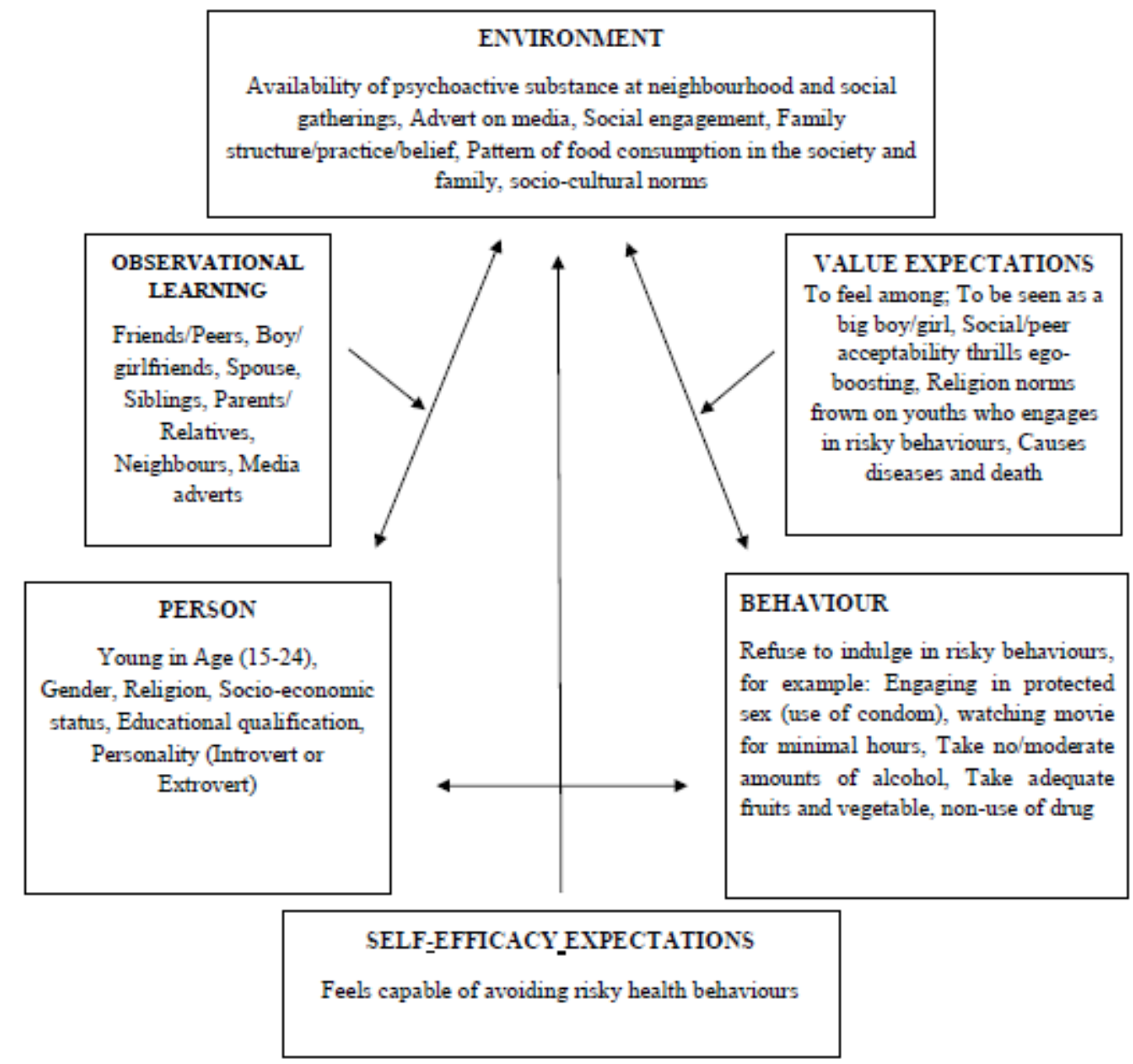

\section{Materials and methods}

\section{Study design}

A community-based, descriptive cross-sectional study design was used for this research which was limited in scope to the investigation of the risky sexual health behaviours among youths in Ibadan NorthWest LGA, Oyo State.

\section{Target population}

The Sample population consisted of youths in Ibadan North-West LGA, Oyo State that consented to participate in the study, who were between the ages of 15-24 years old and had resided for at least 6 months in Ibadan North-West LGA, Oyo State.

\section{Sample size and sampling techniques}

A sample size of 321 was derived using the Leslie-Fischer formula, with a prevalence of $56.5 \%$ from a previous study about sexual behaviours and perception of HIV/AIDS in Nigeria (Fawole, Ogunkan and Adegoke, 2011). To increase representativeness and to make allowance for non-response, the sample size was summed up to 360 .

A multi-stage sampling technique was used in selecting the respondents for this study. Stratified sampling method was used to group the 11 wards present in Ibadan North West local government into three categories: inner core (urban-slum), transitory and peripheral for proper representation of the entire population. Proportionate sampling method was used to select five wards out of the 11 wards present in 
DOI: 10.21522/TIJPH.2013.SE.19.01.Art019

ISSN: 2520-3134

the local government area. Three communities were selected from each of the wards using simple random sampling via balloting system. At each of the selected communities, 24 youths were randomly selected. Respondents that consented were then selected using simple random sampling via balloting system where more than one eligible respondent was present in a house.

\section{Instrument for data collection}

Quantitative method was used to obtain data for this study. The instrument was a semi-structured interviewer administered questionnaire which included both open-ended and close-ended questions. The questionnaire consisted of two main sections and each section of the questionnaire focused on the following:

- Socio-demographic characteristics of the respondents.

- Sexual risky health behaviours practiced by the respondents and reasons for youth engagement in risky health behaviours.

Sexual risky health behaviours were measured on a 26-point scale. Generally, the higher the score, the higher the respondent's participation in risky sexual health behaviours. Scores of 20 points and above were said to have a high level of participation in risky sexual behaviour, scores between 10 and 19 were said to moderately participate in sexual risky health behaviours while scores of 9 and below were said to be have a low participation in risky sexual health behaviours.

\section{Data collection process, management and analysis}

The instrument used was a pretested semi-structured interviewer-administered questionnaire, the questionnaire elicited information about respondents' socio-demographic characteristics, sexual behaviours and factors responsible for such behaviours. Content validity of the instrument was also ensured. To ensure reliability the questionnaire was translated into Yoruba, the language widely spoken in the communities. Also, the draft instrument was pre-tested among in Ibadan-North LGA to ascertain comprehension, acceptability and revision of the instrument. A Cronbach's Alpha correlation coefficient of 0.981 was used to determine the reliability of the instrument.

Three research assistants who were fluent in English and Yoruba languages were recruited and trained for the study. Proper explanations were given to ensure clarity to ensure documentation of valid information. Non-verbal cues were observed which helped to elicit the appropriate responses to the questions. Each copy of the questionnaire was reviewed by research assistants and principal researcher for completion.

Data collected were analyzed with IBM's SPSS version 21, using both descriptive and inferential statistics (Chi-square and Binary logistic regression), which was used to test for significant associations between variables as well as the strength of the associations. Level of significance was considered at pvalue of less than 0.05 for all inferential statistics.

The outcome measures analyzed in the study were sexual behaviour of respondents, some of which were also the risk indicators. Sexual behavior (risk indicators) included sexual activity in the preceding 12 months, previous sexual exposure, early sexual debut, multiple sexual partners, casual sex and unprotected sex (non-use of condom). Likewise, their reasons for engaging in such behaviours was explored, among which included peer pressure, civilization/social and media pressure, curiosity, pleasure/fun, loneliness and many more. Predictors of sexual-risky behaviours was assessed by the investigators using chi square test and binary logistic regression analysis set at $p$-value $\leq 0.05$ to ascertain their association. The respondent's socio-demographic variables used include age, gender, level of education, level of income, religious, marital status, family type (Monogamy/Polygamy), Living arrangement ("Who do you live with most of the times"), Ethnicity and Current status ("What are you doing presently") 


\section{Ethical considerations}

Ethical approval for the study was obtained from Oyo State Ministry of Health Ethics Review Committee prior to commencement of the study. Permission was also obtained from community heads of the study sites. Respondents were assured of confidentiality, privacy and anonymity of information given. Their consent was also obtained before they were recruited into the study.

\section{Results}

The demographic characteristics of the respondents showed that $61.1 \%$ of the respondents were males while $38.9 \%$ were females. Their ages ranged from 15 - 24years with a mean age of $19.15 \pm 2.978$. Majority $(72.2 \%)$ of the respondents were Christians. Another $76.1 \%$ are of Yoruba descent, $89.4 \%$ were single and $2.5 \%$ were respondents who were co-habiting.

The highest level of education attained by respondents was senior secondary level. More respondents had estimated weekly income of 500 naira or below with only $4.4 \%$ earning above $1000-20000$ naira. A majority also (68.9\%) were from a monogamous family while $31.1 \%$ were from a polygamous family.

\section{Sexual experience}

Majority $(71.7 \%)$ of the respondents reported to have boy/girlfriend, among whom almost half (49.7\%) reported to have ever had sex. The age at first sexual intercourse range from five to twenty-four (5-24) years with almost half (46.4\%) who had first intercourse at age 13-16years. A few (5.6\%) had their first intercourse quite early within the age range of 5-8years and the least. The mean age at first intercourse was $14.66 \pm 5.865$.

Most recent sexual activity showed that majority (40.8\%) of the respondents had sexual intercourse with someone the same month of the study. Also, findings from this study showed that majority of the respondents were sexually active.

\section{Sexual-risk behaviour}

To verify if the respondents have ever had sex with a casual friend/acquaintance, three questions were raised. The first question was "who was your most recent sex partner". While addressing the question, majority $(56.4 \%)$ of the respondents reported that their boy/girlfriend was their recent sex partner, and the least $(21.3 \%)$ reported that their most recent sex partner was a casual friend/acquaintance.

The second and third questions to probe this issue were "Ever had sex with a casual friend/acquaintance?" and "Have you had sex with a casual friend in the past 12months?". From the percentage who have ever had sex, more than half $(57.5 \%)$ reported to have ever had sex with a casual friend while $72.8 \%$ said their sexual intercourse with casual friends occurred in the past 12 months.

\section{Number of sex partners}

A majority (31.2\%) of the respondents who had had sex, had at most five sexual partners and at least two sexual partners. The mean number of sexual partners respondents claimed to have had in the last 612 months to the study was 4 .

\section{Contraception and contraceptive use}

It was discovered that of the population of respondents that have ever had sexual intercourse, $20.7 \%$ of them reported not to have ever used any form of protection. 64.8\% reported condom as a form of protection they have ever used while $2.8 \%$ reported the use of local herbs. Also, only $39.1 \%$ of the respondents that stated that they used condoms were occasional users, $68.7 \%$ reported that they did not use condom at their last sexual encounter. 
DOI: 10.21522/TIJPH.2013.SE.19.01.Art019

ISSN: $2520-3134$

\section{Predictors of sexual-risk behaviours}

\section{Sexual experience}

Findings on the association between respondents' socio-demographic variables and ever had sex revealed significant association with all socio demographic variables except level of education and family type. Regression analysis revealed that there is a moderately positive association between gender and sexual experience; males are about 1.5 times more likely than their female counterparts to have had sexual intercourse.

Respondents aged between 15-17 and 18-20 years are 3.8 and 2.1 times respectively less likely than age 21-24 years to have ever had sexual intercourse $(\mathrm{OR}=0.266, \mathrm{CI}=0.126-0.564 ; \mathrm{OR}=0.487, \mathrm{CI}=$ 0.255-0.931 respectively). Also, students are 2.7 times less likely than those that are employed to have ever had sexual intercourse. $(\mathrm{OR}=0.368, \mathrm{CI}=0.160-0.844)$, while respondents whose weekly income was 500 naira and below are about 3.2 times less likely to have ever had sexual intercourse than those whose income was above 5000 naira $(\mathrm{OR}=0.309, \mathrm{CI}=0.113-0.845)$.

\section{Early sexual debut}

Findings on the association between respondents' socio-demographic variables and age at first sexual initiation revealed significant association with age, marital status and level of education; which indicates that they are predictors to early sexual initiation.

There is also a very strong positive correlation between current age and age at sexual debut of respondents, as respondents within age groups of 15-17 and 18-20 years are about 5.7 and 3.1 times respectively more likely than those older than 21 years to have an early sexual debut $(\mathrm{OR}=5.693, \mathrm{CI}=$ 1.205-26.901; 3.067, CI = 1.260-7.465).

Moreover, there is a moderate positive association between level of education and early sexual initiation. Respondents who had no formal education and those with junior secondary education and below are about 2.9 times more likely than those in/with tertiary education to initiate sexual intercourse earlier.

\section{Use of condom}

There is an association between gender and condom use as male respondents were about 2.6 times more likely than their female counterparts to use condoms $(\mathrm{OR}=2.563, \mathrm{CI}=1.171-5.607)$. While respondents within the age group of 15-17 years are 3.6 times less likely than those within age 21-24 years to use condoms $(\mathrm{OR}=0.277, \mathrm{CI}=0.092-0.830)$. Also, respondents living with their parents are 3.5 times more likely to consistently use condoms $(\mathrm{OR}=3.479, \mathrm{CI}=1.675-7.225)$. However, respondents within the ages of 15-17 years are 7.6 times less likely than those within age 21-24 years to use condom at last sexual intercourse $(\mathrm{OR}=0.132, \mathrm{CI}=0.036-0.488)$.

\section{Sexual intercourse with casual partners}

Male respondents were discovered to be about 2.3 times more likely than their female counterparts to have sex with casual partners $(\mathrm{OR}=2.341, \mathrm{CI}=1.183-4.633)$ while students and apprentice are about 3.5 times less likely than those employed to have sex with casual partners $(\mathrm{OR}=0.286, \mathrm{CI}=0.140-0.787)$.

With regards to their current status, those who were both students and apprentice are about 3.5 times less likely than those that were employed to have sex with casual partner.

\section{Multiple sexual partners}

Findings from the study revealed that respondents with at least junior secondary school education and senior secondary education are about 6.2 and 3.5 times respectively more likely than those with tertiary education to have multiple sexual partners $(\mathrm{OR}=6.158, \mathrm{CI}=1.501-25.269$; OR $=3.970, \mathrm{CI}=1.678$ 9.395 respectively). 
Also, male respondents are 2.5 times more likely than their female counterparts to have multiple sexual partners. Regarding their age, respondents aged between 15-17 and 17-20 years are 3.9 and 1.7 times less likely than those within age 21-24 years to have multiple sexual partners. $(\mathrm{OR}=0.257, \mathrm{CI}=0.085$ 0.777; OR $=0.592, \mathrm{CI}=0.525-0.397$ ).

\section{Discussion, conclusion and recommendations}

The duration of continued education has created a big gap between age at puberty and age at marriage, which therefore increases the likelihood of sexual initiation and unprotected premarital sex, thus creating a situation whereby most students are sexually active and have early sexual debuts (Imaledo, Peter-Kio and Asuquo, 2012).

Respondents within the age group 21-24 years were found to engage more in sexual-risky behaviours and are more vulnerable. This agrees with a study carried out among university students of Ilorin, SouthWest of Nigeria, where respondents aged between 20-24 years were sexually active and vulnerable (Fawole, Ogunkan and Adegoke, 2011). It was also reported that more than half of all new cases of HIV infections in the world occur among young people under the age 25 (Onyene, Uzoka, Ikonta and Bakare, 2010). Tendency to engage in sexual-risk behaviour increases with age among youths. This implies that older youths are at most risk of engaging in sexual-risky practices.

\section{Sexual-risk behavior}

Findings from this study also confirmed the occurrence and increase in premarital sex, which could be attributed to delayed marriage while trying to acquire both formal and informal education.

In this study, more males than females are documented to be engaged in sexual intercourse, this may be because males have higher tendency to engage in riskier behaviours than their female counterparts. Similar findings were obtained among undergraduate students of University of Port Harcourt in Nigeria where $52.0 \%$ of the respondents have ever had sex intercourse (Imaledo, Peter-Kio and Asuquo, 2012).

The findings of this survey further agrees with earlier studies that young people in Nigeria are becoming more sexually active, and many of them have poor reproductive health knowledge to practice safe sexual practices. These high sexual activities among young ones have implication for sexual and reproductive health including exposure to the dangers of contracting STIs, including HIV/AIDS, unwanted pregnancies and poorly managed abortion.

The high level of sexual activities can also be attributed to the increasing loss of moral values in many societies. For instance, Nigerian societies are becoming less restrictive towards premarital sex, coupled with peer pressure to experiment, poor access to quality reproductive health information including family life health education (FLHE) and greater permissiveness towards males than females; often girls are more supervised than boys, and because of these male youths are more likely to engage in risky behaviours than females.

The age of sexual debut is low as found in this study. This finding agrees with a study conducted among undergraduate students of University of Port Harcourt where almost half of their respondents had their sexual debut between the ages of 5-24 years (Imaledo, Peter-Kio and Asuquo, 2012). Other possible reasons for early debuts may be the increasing rate of children molestation and paedophilia.

Most respondents in this study who were sexually active had multiple partners. Similar findings were found in a study carried out among undergraduate students of University of Ilorin, Nigeria (Fawole, Ogunkan and Adegoke, 2011). Having multiple sexual partners also has considerable implications for sexual and reproductive health, including HIV and other STIs transmission and it is one of the factors driving the HIV scourge among youths (Baba-Djara, Brennan, Corneliess, Agyarko-Poku, Akuoko, Opoku., et al). Multiple sexual partnerships have been noted to be a high-risk sexual behaviour because of their tendency to increase the risk of HIV transmission through sexual networks (Berry and Hall 2009).

More than half $(57.5 \%)$ of the respondents who were sexually active had ever have sex with casual friends or acquaintance before, while $72.8 \%$ claimed to have sex with casual friends or acquaintance in the last 12 months preceding the study. A similar study carried out among youths in national youth 
DOI: 10.21522/TIJPH.2013.SE.19.01.Art019

ISSN: 2520-3134

service camp Osogbo, Nigeria also identified boy/girlfriend (81.8\%) as the highest reported sexual partners, followed by casual friends (25.2\%), live in partners (24.3\%) and sex workers (7.0\%) (Eyitope, 2014).

A cross-sectional study titled gender-based differences in the high-risk sexual behaviours of young people aged 15-29 in Melilla (Spain) found that concerning the motives for having sexual relations with casual partners, male participants considered opportunity and interest in knowing the other person to be more important than the female participants; whereas more females regarded physical excitement as an important reason for having sexual relations with casual partners (Romero-Estudillo, Gonzalez-Jiménez, Mesa-Franco and Garcia-Garcia, 2014).

Economic hardship has been found to encourage young women to initiate sexual activity at early ages for economic reasons and to sustain the practice in older ages (Oshi, Ezugwu, Oshi, Dimkpa, Korie and Okperi, 2007; Aderibigbe and Araoye, 2008). The use of condom during last sexual exposure in this study is lower when compared with the percentage $58.1 \%$ reported in the study conducted at South western, Nigeria among youth service corps members (Eyitope, 2014).

Prostitution among females as well as males for financial benefits can also be attributed to the increase in sexual activities and early debuts among youths. Wide spread incidences of such sexual activities may increase the risk of reproductive and health problems such as STIs, including HIV/AIDS, it may also put younger women at increased risk of unwanted pregnancy and abortion.

\section{Predictors of sexual-risk behaviour}

The gender of respondents as found in this study, was a predictor to involvement in risky sexual behaviour. This agrees with a study conducted among rural school-going adolescents, where it was observed that gender was a predictor to differences in sexual behaviour; this study stated that more males engaged in risky sexual behaviour than females, partly because of the high level of testosterone in boys, which increases early disposition to sexual activities (Adedapo, Julie and Willy, 2014). Males were reported in a study to be more likely to have multiple partners and experience early sexual initiation than females, and thus they are at an increased risk of contracting and transmitting STDS from partner to partner (Dekeke and Sandy, 2014). This predominance among males could be because less attention is given to males compared to females by parents, as female adolescents and youths are much more restricted socially by their parents and the society than males. Also, given that females bear the grunt of unwanted or unplanned pregnancies, it can be said to be the reasons why most males are reported to be more active sexually than females while a higher use of condoms by males may be as a result societal norm which discourages females from possessing condoms.

Age is another predictor for youth engagement in risky sexual behaviour as younger respondents are more likely than older ones to initiate sexual intercourse early. However, younger respondents are less likely than older ones to ever use condom. This shows that adolescents are more prone to unsafe sexual practices than older youths which could be attributed to peer pressure, curiosity, experimentation, poor access to reproductive health services and lack of some life building skills at this stage of their life. Kanku in 2010 reported that adolescence is characterized by upsurge of such hormones as they begin puberty. On the other hand, older youths are more likely to have multiple sexual partners than younger ones which could be attributed to a high level of self-independence and low parental restriction.

Other predictors are the educational levels of respondents as youth or young persons with only secondary education are more likely to have early sexual debuts and have multiple sexual partners than those who have attained tertiary education. This could be linked to poor access to correct reproductive health information and parental level of education. Parental educational level is also said to be an important predictor of youths' educational and behavioural outcomes (Davis, 2005). Youths of literate parents are reported to be less likely to engage in early sexual risk behaviour, such as early sexual initiation before marriage (Dessalegn, 2006). 
In general, social pressure is another factor influencing risky sexual behaviour among young people and youths; premarital sexual activities are now more socially acceptable in Nigeria than they were several years ago.

\section{Conclusion}

A large number of the youths engage in several sexual-risk health behaviours. These behaviours range from having early sexual debuts to having unprotected sexual intercourse with multiple sexual partners including casual friends. Being youths, they are prone to experimenting sexually, these increases their chances of exposure to sexually transmitted diseases and the trauma associated with teenage pregnancy and poorly managed abortions. The research thus established that demographic variables are significant predictors of sexual-risk behavior among youths.

Despite the strong predictors for sexual-risk behaviours engaged in by youths, it is believed that their behaviour can be positively modified through age appropriate, youth-friendly behavioural change interventions that would serve to educate them on sexual and reproductive health and the consequences of indulging in sexual-risk behaviours.

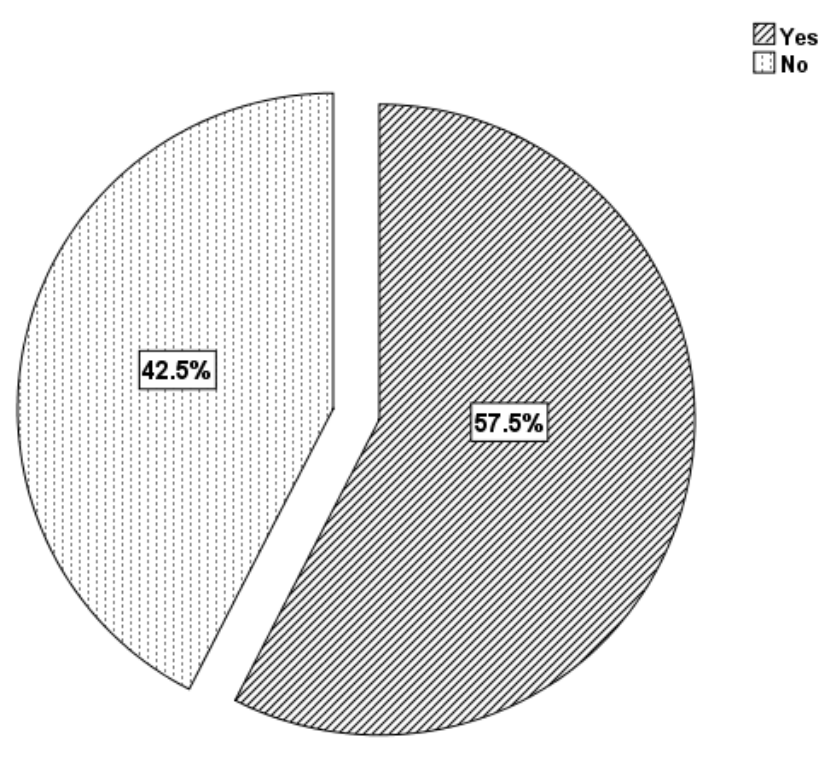

Figure 1. Report of casual sex among respondents 
DOI: 10.21522/TIJPH.2013.SE.19.01.Art019

ISSN: $2520-3134$

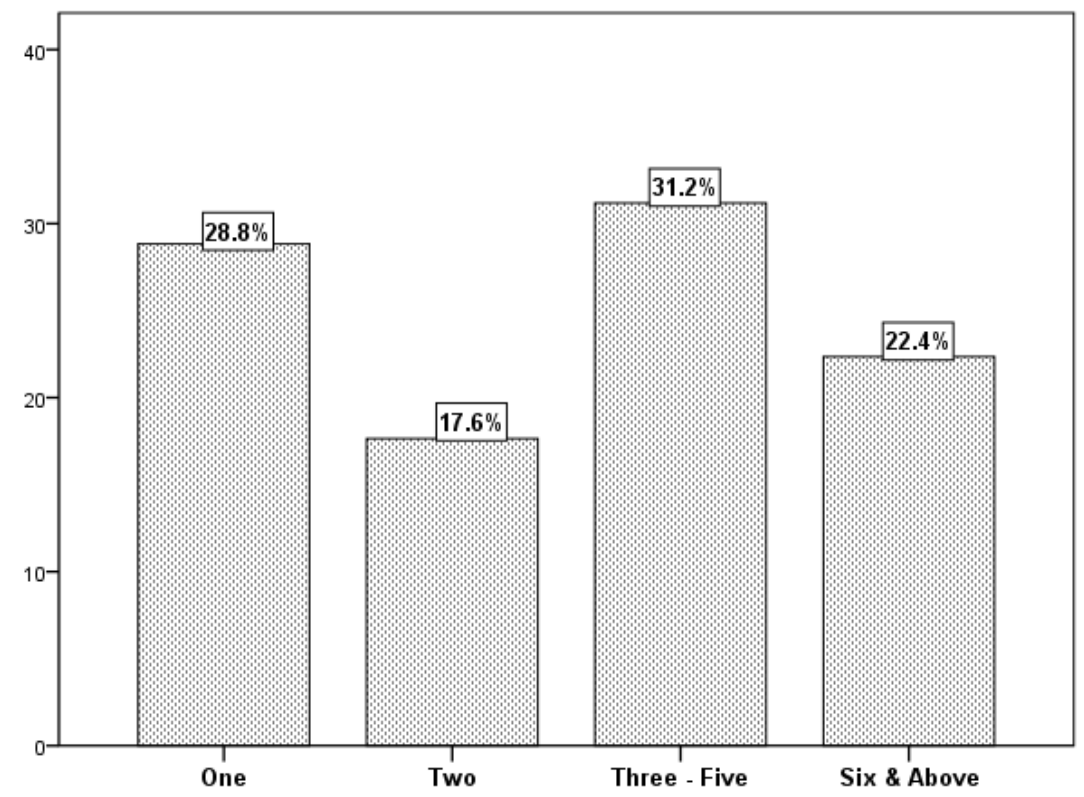

Figure 2. Report of number of sexual partner(s) in the last 6-12 months

\section{References}

[1]. Adebowale, A., Titiloye, M., Fagbamigbe, A. and Akinyemi, O. 2013. Statistical modelling of social risk factors for Sexually Transmitted Diseases among female youths in Nigeria.

[2]. Ahonsi, B. A. 2013. Targeting Youth for HIV Prevention and Care in Nigeria: What Role for Governments? African Journal of Reproductive Health, 17(4). Nigeria Demographic and Health Survey. 2008.

[3]. Aderibigbe, S. A., and Araoye, M. O., 2008. Effect of health education on sexual behaviour of students of public secondary schools in Ilorin, Nigeria. Eur. J. Sci. Res. 24(1), 33-41.

[4]. Adedapo, A.I., Julie, P. I., and Willy, L. 2014. Factors Contributing to the Risk of HIV Infection in Rural School-Going Adolescents. Int. J. Environ. Res. Public Health. (11): 11805-11821.

[5]. Baba-Djara, M., Brennan, A., Corneliess, C., Agyarko-Poku, T., Akuoko, K., Opoku, K.B., et al., Using what you have to get what you want: vulnerability and prevention needs of female post-secondary students engaged in transactional sex in Kumasi, Ghana. Centre for Global Health and Development Boston University, Boston, Massachusetts, USA and Kwame Nkrumah University of Science and Technology Kumasi Ghana.

[6]. Berry, L. and Hall, K. 2009. HIV \& AIDS and STI National Strategic Plan 2007-2011: Multiple sexual partnerships. Cape Town, South Africa: Children's Institute, University of Cape Town

[7]. Centers for Disease Control and Prevention. 2010. Web-based injury statistics query and reporting system.

[8]. Dessalegn, N. 2006. Gudffecha practice as child problem intervention. Oromo city: The case of Ada's Libian District.

[9]. Davis-Kean P.E. 2005. The influence of parent education and family income on child achievement: The indirect role of parental expectations and the home environment. Journal of Family Psychology. 2005;19:294-304.

[10]. Dekeke, G.D. and Sandy, P. T. 2014. Factors influencing sexual risk behavior among senior secondary school students (Youths) in Ethopia. International Journal of Scientific and Research Publications. 4 (8): 1-32.

[11]. Echendu, D. A, Joseph I.B.A, Nkemakolam O. E, Chima I., Akinsewa A. and Ejike O. 2011. Awareness and use of contraception by women seeking termination of pregnancy in south eastern Nigeria. Asian Pacific Journal of Tropical Disease; 71-75

[12]. Eyitope, O. A. 2014. Sexual Behaviour and Risk Perception for HIV among Youth Attending the National Youth Service Camp, Ede, Osun State, Nigeria. Journal of Health Science. 4(1): 1-6 
[13]. Federal Ministry of Health. 2011. Integrated Biological and Behavioral Surveillance Survey (IBBSS), 2010 (Abuja: FMOH).

[14]. Fawole, A. O., Ogunkan, D. V and Adegoke, G. S. 2011. Sexual Behaviour and Perception of Hiv/Aids in Nigerian. University of Ilorin, Nigeria. Global Journal of Human Social Science 11(1); 64-72.

[15]. Imaledo, J. A., Peter-Kio, O. B. and Asuquo, E. O. 2012. Pattern of risky sexual behavior and associated factors among undergraduate students of the University of Port Harcourt, Rivers State, Nigeria. Pan African Medical Journal. 9:97-105.

[16]. Kanku, T. 2010. Attitudes, perceptions and understanding amongst teenagers regarding teenage pregnancy, sexuality and contraception in Taung. SA Fam Pract. 52(6):563-572.

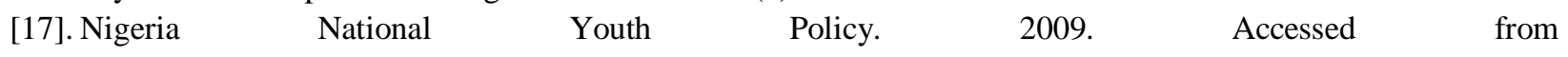
http://www.youthpolicy.org/national/Nigeria_2009_National_Youth_Policy.pdf

[18]. World Health Organization. 2008a. Unsafe Abortion: Global Trend and Regional Estimates of the Incidence of Unsafe Abortion and Associated Mortality in 2000. Nigeria Demographic and Health Survey. 20013.

[19]. Onyene, V., Uzoka, N., Ikonta, N. and Bakare, T. V. 2010. “Tertiary Institution learners' HIV/AIDS sensitisation tool(s) receptivity: Implications for sustainable democracy in Nigeria. Journal of AIDS and HIV Research.2(4):78 - 87.

[20]. Oshi, S.N., Ezugwu, F.O., Oshi, D.C., Dimkpa, U., Korie, F.C. and Okperi, B.O. 2007. Does self-perception of risk of HIV infection make the youth to reduce risky behaviour and seek voluntary counselling and testing services? a case study of Nigerian youth., J. Soc Sci., 14(2), 195-203.

[21]. Romero-Estudillo, E., González-Jiménez, E., Mesa-Franco, M. C. and García-García, I. 2014. Gender-based differences in the high-risk sexual behaviours of young people aged 15-29 in Melilla (Spain): A cross-sectional study. BMC Public Health. 14(745): 1471-2458.

[22]. Terry-McElrath, Y. M., O'Malley, P. M. and Johnston, L. D. (2009). Reasons for drug use among American youth by consumption level, gender, and race/ethnicity: 1976-2005. Journal of Drug Issues. 39:677-714. 